\title{
Index Abstracts
}

Single crystal $X$-ray studies of $\left[\left(\mathrm{H}_{2} \mathrm{NP}\right.\right.$ $\left.\left.\mathrm{Ph}_{2}\right)_{2} \mathrm{~N}\right]^{+}\left[\mathrm{N}\left\{\mathrm{P}(\mathrm{S}) \mathrm{Ph}_{2}\right\}_{2}\right]^{-}$reveal multiple cross hydrogen bonding between the two ions.

The hypervalent tris(catecholato)silicate ion with six different ammonium counter cations have been synthesized and their thermal behaviour investigated. Results indicate counter ion influence on solubility, stability and the formation of spirosilane.

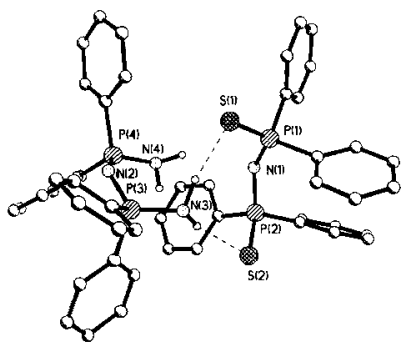

Tuan Q. Ly, Alexandra M. Z. Slawin and J. Derek Woollins

Synthesis and Structural Studies of $\left[\left(\mathrm{H}_{2} \mathrm{NPPh}\right)_{2} \mathrm{~N}^{+}\right][\mathrm{N}\{\mathrm{P}(\mathrm{S})-$ $\left.\left.\mathrm{Ph}_{2}\right\}_{2}\right]^{-}$
J. V. Kingston, Babu Vargheese and M. N. Sudheendra Rao

Synthesis and Characterization of Tris(catecholato) Silicates, $\left[\left(\mathrm{C}_{6} \mathrm{H}_{4} \mathrm{O}_{2}\right)_{3} \mathrm{Si}^{2-}\right.$ with Different Counter Cations - First Pyrolysis Study and $\mathrm{X}$-ray Structure of $\left[\left\{\left(\mathrm{CH}_{3}\right)_{2} \mathrm{CH}_{2} \mathrm{NH}_{2}\right]_{2}\left[\left(\mathrm{C}_{6} \mathrm{H}_{4} \mathrm{O}_{2}\right)_{3}\right.\right.$ Si] $\cdot 2 \mathrm{CH}_{3} \mathrm{CH} \cdot \mathrm{H}_{2} \mathrm{O}$
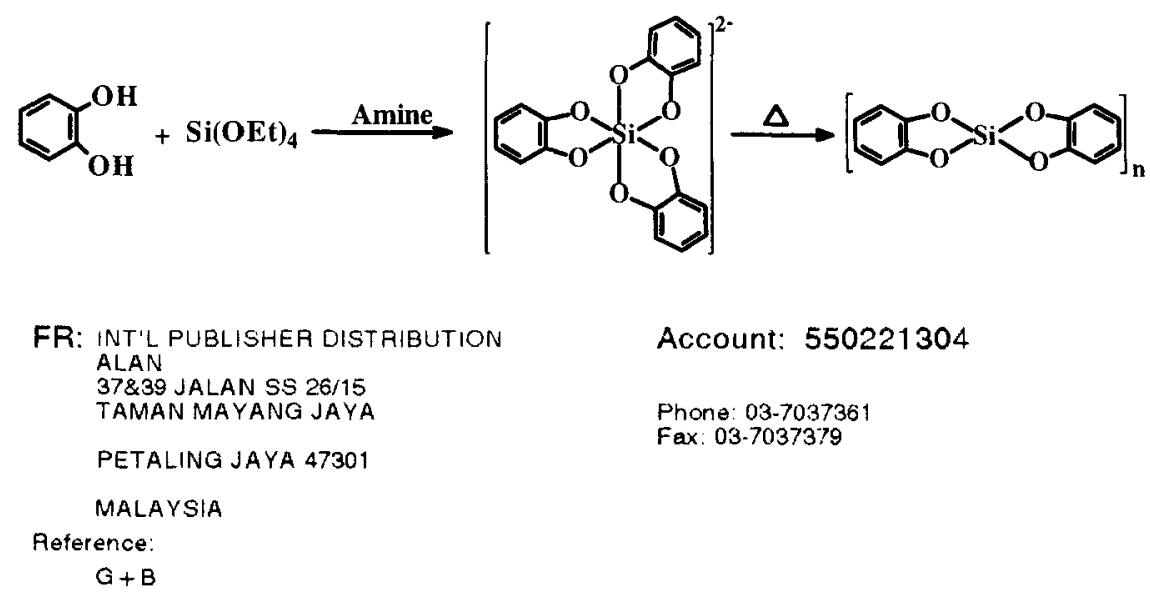

Account: 550221304

Phone: 03-7037361

Cnee Code: MGC AE1 
Since the prime synthesis in 1834 of hexachlorocyclotriphosphazene, $\mathrm{N}_{3} \mathrm{P}_{3} \mathrm{Cl}_{6}$, its electronic structure and morphology constitute a real challenge both for theorists and experimentalists. Thus, we were urged to achieve molecular modelling of $\mathrm{N}_{3} \mathrm{P}_{3} \mathrm{Cl}_{6}$ and relatives by using suitable softwares produced by Biosym Technologies in order to propose CVFF and ESFF parameters for all atoms, mainly for endocyclic $P$ ones which are actually neither $P(I V)$ nor $P(V)$ entities. This approach appeared to be quite convenient for reproducing geometries and conformations of any cyclophosphazenic moiety.

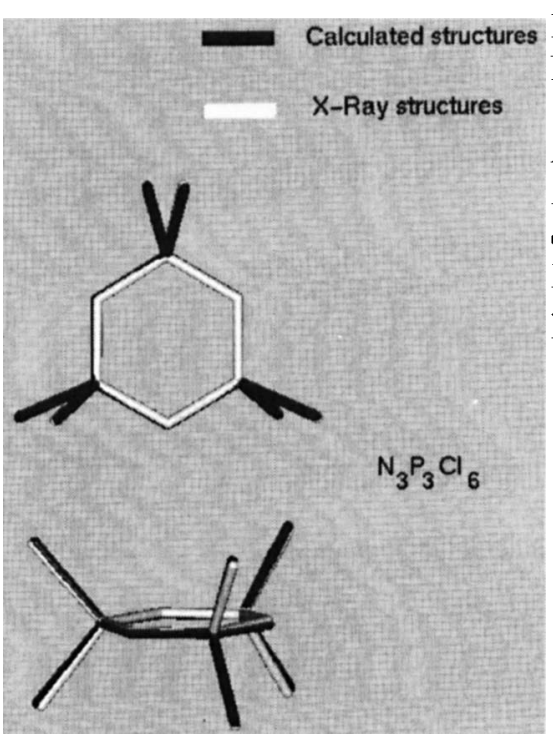

K. Vercruysse, C. Vidal and J.F. Labarre

A Molecular Modelling Approach of the Actual Hybridization State of Endocyclic Phosphorus Atoms in Cyclophosphazenes
In the course of the study of ternary and quaternary sulfides based on an earth-alkali or alkali cation, it is presently reported on two of these, $\mathrm{Rb}_{2} \mathrm{Cu}_{3} \mathrm{FeS}_{4}$ and $\mathrm{Rb}_{2} \mathrm{Cu}_{3} \mathrm{MnS}_{4}$ which are crystalline analogs $\left(\mathrm{ThCr}_{2} \mathrm{Si}_{2}-\right.$ type), and whose magnetic properties are rather different despite a similar electrical behavior.

The reactions of phosphorus pentachloride with vary amounts of 2,4,6-tribromophenol have been studied by ${ }^{31} \mathrm{P}$ NMR spectroscopy. Regardless of the stoichiometry, these reactions yield mixtures of $\mathrm{Cl}_{5-n}$ $\mathrm{P}\left(\mathrm{OC}_{6} \mathrm{H}_{2} \mathrm{Br}_{3}\right)_{n} \quad(n=1-3)$ phosphoranes. All three phosphoranes can non-oxidatively chlorinate dimethyl

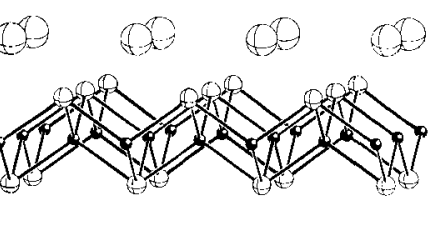
10 A A A

M. Mouallem-Bahout, O. Peña, J. Gaudé, C. Carel, $(\mathrm{Cu}, \mathrm{M})_{2} \mathrm{~S} A$. Ouammou and A. Nadiri Two Quaternary Sulfides $\mathrm{Rb}_{2} \mathrm{Cu}_{3} \mathrm{FeS}_{4}$ and $\mathrm{Rb}_{2} \mathrm{Cu}_{3} \mathrm{MnS}_{4}$ Magnetic Interactions and Electrical Behavior

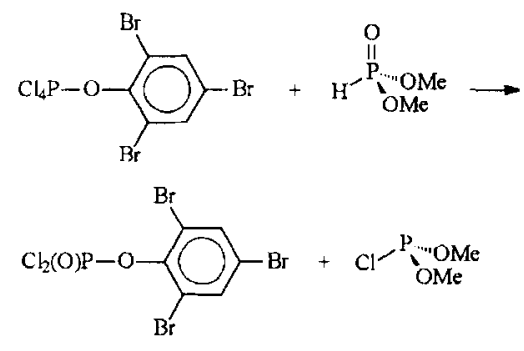

Keith E. Branham, Gray M. Gray, Prakash C. Bharara and Houston Byrd

${ }^{31} \mathrm{P}\left\{{ }^{1} \mathrm{H}\right\} \quad$ NMR Studies of the Preparation of Dichlorotris $(2,4,6$-tribromophenoxy)phosphorane, Trichlorobis $(2,4$, 6-tribromophenoxy)-phosphorane and Tetrachloro $(2,4,6$-tribromophenoxy) phosphorane, and their Nonoxidative Chlorination Reaction with Dimethyl Phosphonate 
Chiral dimethylindiumaminoalkoxides of general formula $\mathrm{Me}_{2} \mathrm{InOR}^{*}$ $\left[\mathrm{OR}^{*}=(+) ;(-)\right.$-2-piperidyl-methoxy (1),(+);(-)-dimethylamino-2-propoxy (2), (S)-(+)-amino-2-propoxy (3), (S)$\alpha, \alpha$-diphenyl-2-pyrrolidinyl-methoxy (4)] have been prepared by reaction of $\mathrm{Me}_{3}$ In with the corresponding aminoalcohols $\mathrm{HOR}^{*}$ and characterized by ${ }^{1} \mathrm{H}$ and ${ }^{13} \mathrm{C} \mathrm{nmr}$ spectroscopy and $\mathrm{X}$-ray crystallography. Dimeric molecules of 1-4 are composed of two $\mu^{2}$ O-bridged chelating rings, the latter formed due to $\mathrm{N}$-In donor-acceptor interaction. This geometry is comparable with that of aluminium and gallium analogues previously investigated. In the case of 1 and 4 , the formation of the $\mathrm{N}$ - In bond proceeds stereospecifically. The absolute structure of $\mathbf{3}$ and $\mathbf{4}$ was confirmed by refinement of the Flack parameter.

Various methods of synthesizing, phase states, physical properties, structure, spectral features, chemical properties and application of main group III element derivatives of phosphorus $(V)$ thioacids with the $\mathrm{P}(\mathrm{S}) \mathrm{SE} \quad(\mathrm{E}=\mathrm{B}, \mathrm{Al}, \mathrm{Ga}, \mathrm{In}) \quad$ structural fragment are reviewed.

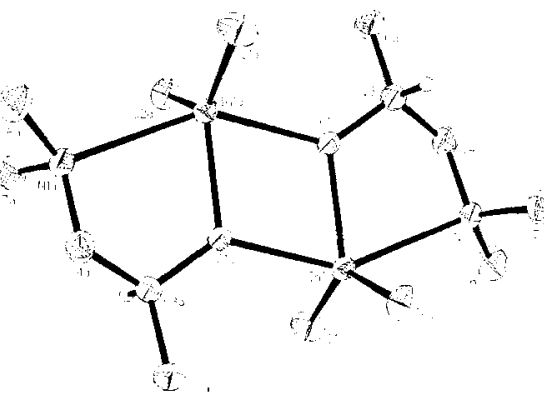

Elmar Hecht, Thomas Gelbrich, K.-H. Thiele Joachim Sieler

Chiral Dimethylindium Aminoalkoxides

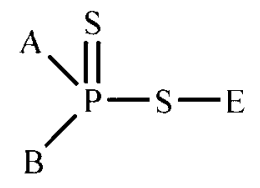

$$
\mathrm{E}=\mathrm{B}, \mathrm{Al}, \mathrm{Ga}, \mathrm{In}
$$

$\mathrm{A}, \mathrm{B}=\mathrm{O}-\mathrm{Alk}, \mathrm{Alk}, \mathrm{Ar}$

$\mathrm{A}-\mathrm{B}=\mathrm{O}-$ Alkylene $-\mathrm{O}$
Il'yas S. Nizamov and Elvira S. Batyeva

Group 13 Element Derivatives of Pentavalent Phosphorus Thioacids. Synthesis, Structure and Properties
New boron derivatives of dithiophosphonic acids were obtained in the reactions of Lawesson's reagent and

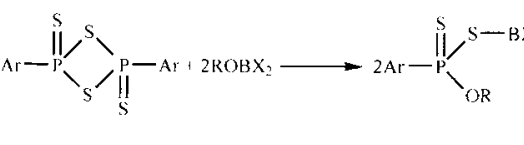
its 4-ethoxyphenyl homologue with trialkyl borates and $\mathrm{O}$-isobutyl diphe- $\mathrm{Ar}=4-\mathrm{MeOC}_{6} \mathrm{H}_{4}, 4-\mathrm{EtOC}_{6} \mathrm{H}_{4} ; \mathrm{X}=\mathrm{OR}$, Ph nylborate. Low frequency ultrasound $\mathrm{R}=\mathrm{i}-\mathrm{Pr}, \mathrm{i}-\mathrm{Bu} . \mathrm{t}-\mathrm{Bu}$ irradiation (frequency $22 \mathrm{kHz}$, power $130 \mathrm{Wt}$ ) leads to reduction in reaction temperature and time in the reactions studied. The prepared compounds were identified by $I R,{ }^{1} \mathrm{H}$, and ${ }^{31} \mathrm{P}$ NMR and mass spectra as well as elemental analyses.
Il'yas S. Nizamov, Gul'nur G. Sergeenko, Elvira S. Batyeva, Nail M. Azancheev and Vladimir A. $\mathrm{Al}^{\prime}$ fonsov

Reactions of 1,3,2,4-Dithiadiphosphetane-2,4-disulfides with Alkyl Borates 
The reaction of 1,4-dilithiotetraphenylbutadiene with germanium(IV) chloride and tin(IV) chloride affords heterocycles $\mathrm{Ph}_{4} \mathrm{C}_{4} \mathrm{GeCl}_{2}, \mathrm{I}$ and $\mathrm{Ph}_{4} \mathrm{C}_{4} \mathrm{SnCl}_{2}$, II. Compounds I and $\mathbf{I I}$ r which feature a planar tetraphenylbutadiene backbone, were characterized by elemental analyses, ${ }^{1} \mathrm{H}$ and 13CNMR spectroscopy and single crystal X-ray diffraction.

The title ruthenium complex (1) was found to catalyze the hydrosilylation. and/or dimerization of phenylacetylene in the presence of a variety of hydrosilanes. Chlorosilanes favored the formation of $\beta$-silylstyrenes while $\mathrm{HSiEt}_{3}$ favored the formation of 1,4diphenylbuteneyne. Z-isomers were the major product regardless of the substituents on silicon.

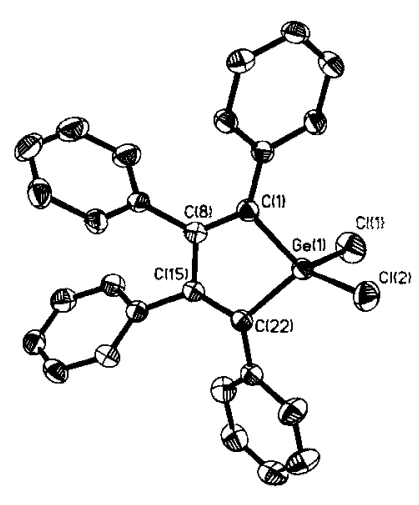

Synthesis and Molecular Structure of Germanium and Tin Tetraphenylbutadienyl Based Heterocyclic Halides

Sonya D. Goodwin, Pingrong Wei, Brent Beck, Jianrui Su and Gregory H. Robinson
Nicholas M. Yardy and Frederick R. Lemke

$\mathrm{RuCl}_{2}\left(\mathrm{PPh}_{3}\right)_{3}$ Catalyzed $\mathrm{Hy}-$ drosilylation and Dimerization of Phenylacetylene in the Presence of Various Hydrosilanes

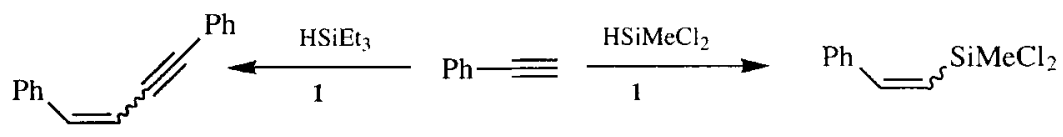

